\title{
Influence of Grain Structure on the Deformation Mechanism in Martensitic Shear Reversion-induced Fe-16Cr-10Ni Model Austenitic Alloy with Low Interstitial Content: Coarse-grained versus Nano-grained/Ultrafine-grained Structure
}

\author{
V.S.A. Challa ${ }^{1}$, R.D.K. Misra ${ }^{1}$, M.C. Somani ${ }^{2}$, Z.D. Wang $^{3}$ \\ ${ }^{1}$ Laboratory for Excellence in Advanced Steel Research, \\ Department of Metallurgical, Materials Engineering, and Biomedical Engineering, \\ University of Texas at El Paso, \\ El Paso, TX 79968, USA \\ ${ }^{2}$ Center for Advanced Steels Research, The University of Oulu, P.O. Box 4200, 90014 Oulu, Finland \\ ${ }^{3}$ State Key Laboratory for Rolling and Automation, Northeastern University, \\ 3-11 Wenhua Road, Shenyang 110819, China
}

\begin{abstract}
$\underline{\text { Abstract }}$
Nanograined/ultrafine-grained (NG/UFG) materials characterized by high strength-high ductility combination are excellent vehicles to obtain an unambiguous understanding of deformation mechanisms vis-à-vis their coarse-grained counterparts. In this context, the innovative concept of phase reversion-induced NG/UFG structure enabled achieving high strength besides comparable ductility, for instance, in metastable austenitic stainless steels. In the phase reversion process, severe deformation of austenite at room temperature (typically $\sim 60-80 \%$ ) transforms facecentered cubic austenite $(\gamma)$ to body centered cubic martensite $\left(\alpha^{\prime}\right)$. Upon annealing, martensite reverts to austenite leading to extensive grain refinement. The objective of the present study to fundamentally understand the deformation mechanisms in NG/UFG structure in relation to that of the coarse-grained (CG) structure was accomplished by combining depth-sensing nanoscale experiments on an $\mathrm{Fe}-16 \mathrm{Cr}-10 \mathrm{Ni}$ model austenitic alloy conducted at different strain rates, followed by the study of structural evolution in the deformed zone using transmission electron microscopy (TEM). In the high strength NG/UFG steel (YS 585 MPa), stacking faults and nanotwins contributed to the enhanced ductility (El 35\%), while in the case of low strength (YS 260 MPa) coarse-grained (CG) counterpart, ductility was also high (El $\sim 40 \%$ ), but chiefly due to strain-induced martensite, which points to a clear case of grain size effect (and the corresponding level of strength). The distinct change in the deformation mechanism from stacking faults and twinning-induced plasticity (TWIP) in the NG structure to transformationinduced plasticity (TRIP) in the CG structure is elucidated in terms of austenite stability-strain energy relationship. The insights on the relationship between grain structure (and strength) and deformation mechanisms are envisaged to be important in providing a new direction for the futuristic design of high strength-high ductility NG/UFG materials such as austenitic stainless steel and twinning induced plasticity steels.
\end{abstract}

Keywords: Austenitic stainless steel; nanograined structure; deformation mechanism; electron microscopy; twinning.

Corresponding author: Professor R.D.K. Misra

Tel: 001-915-747-8679, Fax: 001-915-747-8036,Email: dmisra2@utep.edu 


\section{Introduction}

Grain refinement is an important approach that simultaneously improves both strength and toughness of engineering alloys [1,2]. Thermo-mechanical controlled processing (TMCP) is one of the primary methods to obtain grain refinement, besides refinement of microstructural constituents. In the particular instance of body-centered cubic (bcc) ferrous alloys, TMCP and microalloying were combined to obtain ferrite grain size less than $5 \mu \mathrm{m}$ [3-6]. However, there is a limit to which grain refinement can be accomplished via TMCP. To some extent, this limitation can be overcome by adopting severe plastic deformation that leads to submicron or ultrafinegrained structure in metals and alloys $[7,8]$, but this may affect negatively the tensile ductility and toughness.

We have recently achieved high strength-high ductility combination in NG austenitic alloys by combining controlled deformation and phase reversion annealing [9-13]. The innovative concept of phase reversion-induced nano/submicron-grained structure involves deformation at room temperature $(\sim 60-80 \%)$ of metastable $(\mathrm{FCC})$ austenite $(\gamma)$ to strain-induced (BCC) martensite $\left(\alpha^{\prime}\right)$. Upon annealing at $700-925^{\circ} \mathrm{C}$ for short durations of $\sim 10-100 \mathrm{~s}$, martensite reverts to austenite via martensitic shear mechanism in a $16 \mathrm{Cr}-10 \mathrm{Ni}$ austenite steel, without influencing the texture [9-12]. The shear reversion process involved the following three stages: (a) transformation of strain-induced martensite to reverted austenite laths with high dislocation density, (b) formation of dislocation cell structure and transformation to reverted defect-free austenite grains, and (c) coalescence of sub-grains to form a NG/UFG structure. The success of phase reversion approach to obtain NG/UFG structure was previously demonstrated to be governed by predominance or maximization of dislocation cell-type structure in the severely deformed metastable austenite [10]. An important feature of phase reversion concept is that it enables us to fundamentally explore deformation mechanisms in a single material from NG to coarse-grained (CG) regime, depending on the process parameters (cold deformation and annealing temperature-time sequence).

There is a continued interest to understand the deformation mechanisms in NG alloys because the understanding is fragmented $[14,15]$. It is believed that deformation mechanisms in nanostructured metals and alloys can be significantly different from those operating in the CG structure. The high strength of NG metals in relation to the CG counterpart has led us to believe that the predominant mode of plastic deformation in ductile CG materials mediated by the 
grouped activity of dislocations (e.g., formation of dislocation pile-ups and cells) is essentially suppressed in the NG materials, where partial dislocation emission from grain boundaries may be operative $[14,16]$. Thus, it is envisaged that extensive grain refinement down to the NG/UFG regime and consequent increase in yield strength at comparable ductility level must involve a deformation mechanism that is significantly different from the CG structure.

The high ductility of CG austenitic stainless steels is due to gradual transformation of austenite to martensite, which delays the onset of localized necking and increases the strain hardening rate [17-19]. But, in a sharp contrast to the deformation behavior of CG austenite, we underscore in the study described here that the grain size impacts the mechanical stability of austenite in such a manner that the transformation of austenite to martensite is suppressed in the $\mathrm{NG} / \mathrm{UFG}$ austenite. In this regard, the combination of severe cold deformation at room temperature and phase reversion annealing was applied to an experimental model $\mathrm{Fe}-16 \mathrm{Cr}-10 \mathrm{Ni}$ alloy with low interstitial content of 0.008 wt.\% carbon and nitrogen content of $0.004 \mathrm{wt} . \%$, to explicitly identify the deformation mechanism in a high strength-high ductility combination NG material as a function of strain rate and compare with that of CG counterpart under identical experimental conditions. Owing to low interstitial content in the experimental alloy, the effect of carbon and nitrogen on the constitutive flow behavior is excluded. Besides, the possibility of formation of secondary precipitates that not only may influence the kinetics of nucleation of austenite grains but also the deformation behavior, is significantly reduced. Thus, we expect the study to provide an unambiguous clarification of deformation mechanisms.

In the present study, nanoscale deformation experiments using a nanoindenter were planned to identify the microstructural mechanisms operating during deformation. The underlying reasons for using nanoindentation [20-25] are: the indenter tip ( $20 \mathrm{~nm}$ radius) is too small to produce a highly stressed volume beneath the indenter. The basic processes operating in a small volume of the material are envisioned to have a low probability of encountering pre-existing dislocation prior to the initiation of plastic deformation. Moreover, the tested volume is scalable with respect to the microstructure $[20,21]$.

\section{Experimental: Materials and Methods}

A model experimental Fe-16Cr-10Ni alloy having a nominal composition of $\mathrm{Fe}-0.008 \mathrm{C}$ $0.01 \mathrm{Si}-0.04 \mathrm{Mn}-15.9 \mathrm{Cr}-10 \mathrm{Ni}-0.004 \mathrm{~N}$ (in wt.\%) was vacuum cast and rolled. The strips of $\sim 1.5$ 
$\mathrm{mm}$ were cold rolled in a number of passes in a laboratory rolling mill leading to $\sim 74 \%$ thickness reduction and subsequently annealed in the temperature range of $800-925^{\circ} \mathrm{C}$ for $10-100 \mathrm{~s}$ using a Gleeble 1500 thermo-mechanical simulator to obtain reverted NG/UFG austenite structure. The annealing experiments were carried out with strips of $120 \mathrm{~mm}$ x $25 \mathrm{~mm}$ (thickness $0.39 \mathrm{~mm}$ ). The details of phase reversion process have been described by us elsewhere [9-12]. In brief, the concept of phase reversion-induced nano/submicron-grained structure involves cold deformation at room temperature $(\sim 60-80 \%)$ of metastable $(\mathrm{FCC})$ austenite $(\gamma)$ to strain-induced (BCC) martensite $\left(\alpha^{\prime}\right)$. Upon annealing at $800-925^{\circ} \mathrm{C}$ for short duration of $\sim 10-100 \mathrm{~s}$, martensite reverts to austenite via shear mechanism in $\mathrm{Fe}-16 \mathrm{Cr}-10 \mathrm{Ni}$ austenitic steel, without influencing the texture. Room temperature tensile properties were determined using specimens that were machined to a profile of $25 \mathrm{~mm} \times 25 \mathrm{~mm}$ with a $20 \mathrm{~mm}$ gage length. Tensile tests were conducted at a strain rate of $3 \times 10^{-3} / \mathrm{s}$.

Two different methods were tried to determine the grain size, viz., average grain size and weighted average grain size. The average austenite grain size was determined by analyzing at least 100 grains in the micrographs to determine the mean linear intercept grain size, $\bar{d}$. In the second method, where the focus was grain size distribution, the weighted average grain size, $\bar{d}_{w}$, was measured. Approximately 100 grains were sorted in successive bins of $250 \mathrm{~nm}(0.25 \mu \mathrm{m})$ in size. A bin of size $250 \mathrm{~nm}(0.25 \mu \mathrm{m})$ was selected in order to optimize the statistical data [26]. A small bin size generally results in poor statistical accuracy, while a large bin size may mask the effect of small grains. The bins were defined as $B=\left(b_{1}, b_{2}, \ldots, b_{N}\right)$, where $b_{1}=0$ to $250 \mathrm{~nm}(0.25$ $\mu \mathrm{m}), \mathrm{b}_{2}=0.25 \mu \mathrm{m}$ to $0.50 \mu \mathrm{m}, \ldots, \mathrm{b}_{\mathrm{N}}=24.75 \mu \mathrm{m}$ to $25.00 \mu \mathrm{m}$. Next, the number of grains belonging to each of the $i$ th bin was counted from a sample of 100 grains. The number of grains in the $i$ th bin was referred as $n_{i}$ and dividing it by the total number of grains, $\mathrm{N}$, the weight of the ith bin is given by [26]:

$$
w_{i}=\frac{n_{i}}{N}
$$

Furthermore, the square root of the areal mean of $n_{i}$ grains in the $i$ th bin gives the average grain size, $\bar{d}_{i}$, for the $i$ th bin. Knowing $\bar{d}_{i}$ and $w_{i}$, the weighted average grain size of the sample was calculated by [26]: 


$$
\bar{d}_{w}=\sum_{i-1}^{N} w_{i} \bar{d}_{i}
$$

Given that the primary objective of the study described here concerns elucidation of deformation mechanisms, the nanoindents were examined by TEM, for which the following procedure was adopted [11]. First, disks of $\sim 3 \mathrm{~mm}$ dia were punched from the experimental steel and partially electropolished in a refrigerated electrolyte of $10 \%$ perchloric acid in acetic acid at $25 \mathrm{~V}$ for $\sim 30 \mathrm{~s}$ to obtain a shining surface in the center part of the $3 \mathrm{~mm}$ disk. Next, the nanoindentation experiments were carried out in displacement-controlled mode at strain rates in the range $0.05-1 / \mathrm{s}$ using partially jet polished surface. The maximum displacement was set at 200 $\mathrm{nm}$. The nanoindenter system (MTS XP) consisted of a Berkovich three-sided pyramidal diamond indenter with a nominal angle of $65.3^{\circ}$ and indenter tip radius of $20 \mathrm{~nm}$. An array of indents of matrix $12 \times 12$ was defined with the indent gap of $10 \mu \mathrm{m}$ [11]. After the indentation experiments, the final electropolishing of the disks was carried out only from the side opposite to the indented surface. Using this procedure, the area surrounding the indents, which is present along the final jet-polished hole, was electron transparent to study the deformation behavior using a TEM (Hitachi H9500, $300 \mathrm{kV}$ ).

There is a possibility that small indentations may have a strain-gradient distribution within the plastic zone. Thus, during TEM examination, we focused approximately in the center of the plastic zone. The plastic zone size was similar for both CG and NG/UFG because of similar elongation-to-fracture and strain hardening behavior [11]. We accomplished this by moving the electron beam and/or specimen foil in small steps from region close to the indenter tip to the region where deformation was nearly absent. This enabled approximate identification of the center of the plastic zone. Thus, it can be assumed that the deformation structures presented here are from a region close to the center of the plastic zone.

The indentation strain is the ratio of the contact radius and the indenter radius, such that the contact radius is related to the displacement. The displacement for both the CG and NG/UFG structures at the strain rates studied was in the narrow range of 175-200 nm, consistent with similar elongation-to-fracture of the two steels. But as expected, the load required to obtain displacement was greater for the NG/UFG steel in relation to the CG counterpart. Based on finite element analysis of nanoindentation process with Berkovich nanoindenter, the equivalent 
indentation plastic strain was found to vary in the range $\sim 0.002-0.2$ and the correspoinding indentation strain in the center of the plastic zone was estimated to be $\sim 0.05$.

\section{Results and Discussion}

\subsection{Starting Microstructure and Strain Rate Sensitivity Experiments}

The optical and transmission electron micrographs of starting CG and NG/UFG steels are presented in Figure 1, respectively. When we compared the average grain size $\bar{d}$ with the weighted average grain size, $\bar{d}_{w}$, the $\bar{d}_{w}$ value differed from $\bar{d}$ by $\sim 5 \%$ for the NG sample and less than $\sim 1 \%$ for the $C G$ sample. This suggests that the weight due to coarser grains is significant in determining $\bar{d}_{w}$ for the CG structure [26]. Irrespective of this, there were insignificant differences between the two methods. For the CG steels, the weighted average grain size $\left(\bar{d}_{w}\right)$ was $\sim 16 \mu \mathrm{m}$. On the other hand, the NG/UFG steel (cold rolled to $74 \%$ reduction and annealed at $850^{\circ} \mathrm{C}$ for $100 \mathrm{~s}$ ) the grain size was $\sim 250 \mathrm{~nm}$.

The yield strength of the NG/UFG steel was $585 \mathrm{MPa}$, which was more than twice that of CG steel (260 MPa), but the elongation-to-failure was practically similar (NG/UFG: 35\% and CG: $40 \%$ ). The combination of NG structure and mechanical properties, therefore, is excellent. Considering the mechanical property data of CG and NG/UFG steels, it is believed that there must be differences in the deformation mechanisms, which should be reflected in strain rate sensitivity. Thus, we briefly present the strain rate sensitivity data acquired from nanoscale deformation experiments, prior to the discussion of deformation mechanism and related microstructural evolution.

Depth-sensing deformation experiments via nanoindenter were carried out at strain rates in the range $0.05-1 \mathrm{~s}^{-1}\left(0.05,0.1,0.5\right.$, and $\left.1 \mathrm{~s}^{-1}\right)$. Generally, the strain rate data is best realized in terms of hardness, and is summarized in Figure 2. The hardness data presented in Figure 2 is an average of at least 10 measurements, where the indentation strain rate $\dot{\varepsilon}$ is defined as the displacement rate (dh/dt) divided by the displacement, and is given by [27]:

$$
\dot{\varepsilon}=(1 / h) d h / d t
$$

It is apparent from Figure 2 that the NG steel exhibits greater sensitivity in comparison to CG steel under identical experimental conditions. For instance, the average indentation hardness at the lowest strain rate of $0.05 \mathrm{~s}^{-1}$ was $\sim 2.2 \mathrm{GPa}$ for CG steel and $\sim 3.2 \mathrm{GPa}$ for NG/UFG steel. 
The strain rate sensitivity is given by $[28,29]$ :

$$
m=\sqrt{3} k T / v \sigma=3 \sqrt{3} k T / v \mathrm{H}
$$

where $m$ is a non-dimensional strain rate sensitivity index, $k$ is the Boltzmann constant, $T$ is the absolute temperature, $\sigma$ is the flow stress, $\mathrm{H}$ is the hardness (which is generally assumed to be three times the flow stress) and $v$ is the activation volume, which is the rate of decrease of activation enthalpy with respect to flow stress at a fixed temperature:

$$
v=\sqrt{3} k T\left(\frac{\partial \ln \dot{\varepsilon}}{\partial \sigma}\right)
$$

where $\dot{\varepsilon}$ is the strain rate. The strain rate sensitivity determined from Figure 2 was 0.14 for CG steel and 0.19 for the NG steel. If we consider the strain rate sensitivity data for $\mathrm{Cu}$ and $\mathrm{Ni}$ [28], for ultrafine- to nanocrystalline regime, $\mathrm{m} \approx 0.022$ at a grain size of $\sim 100 \mathrm{~nm}$ and $\mathrm{m} \approx 0.012$ at a grain size of $\sim 1000 \mathrm{~nm}$. Thus, the values of $\mathrm{m}$ are high for both CG and NG steels. This behavior is consistent with small differences in the strain hardening behavior of NG and CG steels during tensile tests. Maximum strain hardening rate for NG and CG steels were $\sim 3100 \mathrm{MPa}$ and $\sim 2750$ $\mathrm{MPa}$, respectively, in spite of differences in deformation mechanism (sections 3.2 and 3.3). Deformation twinning contributed to strain hardening in NG steel, and strain-induced martensitic transformation induced a similar effect in the CG counterpart.

In the past the small differences in strain rate sensitivity has been discussed in terms of thermal drift [30]. We used a nanoindenter system, which adopts continuous stiffness approach at frequencies greater than $40 \mathrm{~Hz}$, and is therefore less sensitive to thermal drift. Irrespective of this, small thermal drifts of $\sim 0.05 \mathrm{~nm} / \mathrm{s}$ can still appear. The time of strain rate experiments varied from $\sim 10 \mathrm{~s}$ (strain rate of $1 \mathrm{~s}^{-1}$ ) to $\sim 100 \mathrm{~s}$ (strain rate of $0.05 \mathrm{~s}^{-1}$ ). At a drift rate of 0.05 $\mathrm{nm} / \mathrm{s}$, the maximum drift is only $\sim 6 \mathrm{~nm}$ and is $\sim 3-4 \%$ of the total displacement $(\sim 175-200 \mathrm{~nm})$. The $\sim 6 \mathrm{~nm}$ drift is extremely small and can be ignored in our case. Thus, the difference in ' $\mathrm{m}$ ' observed between NG and CG steels is believed to reflect differences in deformation mechanism (mechanical twinning in NG steel versus strain-induced transformation in CG steel) (sections 3.2-3.4).

Using equation 5 and Figure 2, the activation volume for the CG steel was $\sim 50 \mathrm{~b}^{3}$, where $\mathrm{b}$ is the magnitude of the Burgers vector, and for NG structure was $28 \mathrm{~b}^{3}$. The difference of $\sim 1.7$ times in the activation volume, though not too large must be reflected in the deformation mechanisms of NG and CG steels (sections 3.2 and 3.3). 


\subsection{TEM Study of Microstructural Evolution with Strain Rate for the NG Steel}

A summary of transmission electron microscopy studies made approximately in the center of the plastic zone size at different strain rates is presented in Figure 3. A network of intersecting twins and SFs was observed almost in the entire plastic zone. In a number of instances at all strain rates, twins and SFs remained in the grain interior with Shockley partial dislocations located at the front tips of twins and SFs (Figure 3).

In Figure 3, the SFs bounded by partials are indicated by symbols ' $\mathrm{P}$ '. The dislocations were trapped at the intersection of SFs and/or of twins (Figure 3b) and increased with strain rate. This is expected to encourage intragranular dislocation-dislocation interactions, associated with the glide of extended dislocations on different slip systems. Interestingly, there was a sharp increase in SFs and twin area fraction with increasing strain rate, which led to a consequent decrease in the spacing between adjacent SFs or twins.

A minimum of 10 micrographs were assessed to determine the area fraction of twins and SFs. Based on ASTM linear-intercept method, the SF lamellae thickness measurements along the [110] orientation indicated a wide distribution from several nanometers to tens of nanometers. In fact, in this orientation only (111) and (111) twins were edge-on, while (111) and (111) twins were inclined to the surface. We defined twin density as the total area of twin boundaries (TBs) per unit volume. Figure 4 shows high magnification micrographs of extensive twinning that was clearly observed in NG steel. The evolution of SF and twin area fraction, and ratio of SF/twin as a function of strain rate are presented in Figure 5. The top plot is for SFs, middle plot for twins, and the bottom plot is the ratio of area fractions of SFs to twins (SF/twin ratio). It is clear from Figure 5 that the area fraction of both SFs and twins increased monotonically with increase in strain rate, and the $\mathrm{SF} / \mathrm{twin}$ ratio decreased (or twin/SF ratio increased) with increase in strain rate. This suggests that strain rate increased twinning because the twinning stress is low at high strain rates. Moreover at high strain rates, the proliferation of dislocations and their long range migration becomes difficult such that twins require less microspacing to initiate than dislocation slip.

The objective here is to elucidate that twinning in the NG austenitic stainless steel is related to higher stability of austenite in the NG structure (section 3.4). Based on Figure 3 and from the available knowledge, we envisage that a twin nucleates by virtue of multiple partial dislocation emission, which does not require rearrangement of dislocations [31-34]. Under these 
circumstances, dissociation of dislocation gives rise to a stationary partial and a twinning partial; and twin growth involves the twinning partial undergoing double cross-slip [34]. More recently, it was shown that high density of SFs with nanoscale spacing acted as barriers that pinned dislocations and enhanced strain hardening, leading to high ductility [35]. This is consistent with our observations where SFs were effective in retaining ductility in the NG material. Twin boundaries (TBs) are also potential sites at which dislocations pile-up with a consequent increase in strain hardening ability and retention of high elongation. Thus, twinning is an effective approach to improve strength and ductility of NG/UFG metals and alloys with significant strain hardening ability.

It is important to briefly discuss the effect of orientation of grains on twinning, considering that it was recently proposed that twinning might be influenced by grain orientation [36-40]. The effect of grain orientation on twinning was studied in a relatively high-Mn TWIP steel of nominal composition (in wt.\%) of Fe-33Mn-3Al-3Si [38,39]. During tensile straining, deformation twinning was favored in grains oriented close to $<111>/ /$ tensile axis, because of high Schmid factor, whereas twinning was prevented in compression because the grains rotated toward $<101>$ axis, which rendered them unfavorably oriented for twinning (low Schmid factor). Recently, Raabe's group provided an understanding of orientation effect on twinning via study of fine-grained (average grain size $3 \mu \mathrm{m}$ ) and coarse-grained (average grain size $50 \mu \mathrm{m}$ ) Fe-22Mn0.6C (wt.\%) TWIP steel [36]. Twins were observed in grains of size less than $1 \mu \mathrm{m}$ [36], contrary to Ueji's observations [37]. Raabe's group made an interesting observation that grain orientation effect on deformation twinning was strong only at low strain of 0.03 logarithmic strain, consistent with Schmid's law. But at high logarithmic strain of 0.3, the grain orientation effect was absent, such that grains were both favorably and non-favorably oriented to deformation axis. Given the contradictory findings of Ueji et al. [37], who observed a significant reduction in twinning in Fe-31Mn-3Al-3Si (wt.\%) TWIP steel, it is important that two different materials are compared at similar grain size, and the effect of stacking fault energy (SFE) is not ignored [36]. Based on the aforementioned discussion, the difference in the extent of deformation twinning observed by Ueji et al. [37] and Raabe's group [36] in fine grained TWIP steel is attributed to stacking fault energy (SFE) difference between the two materials, i.e., 40 $\mathrm{mJ} / \mathrm{m}^{2}$ (Fe-31Mn-3Al-3Si: Ueji et al. [37]) versus $22 \mathrm{~mJ} / \mathrm{m}^{2}$ (Fe-22Mn-0.6Si: Raabe's group 
[36]), implying the important contribution of SFE on twinning. In our case, the SFE of NG and CG $16 \mathrm{Cr}-10 \mathrm{Ni}$ stainless steel is $15-20 \mathrm{~mJ} / \mathrm{m}^{2}$ (SFE per se is constant for a given material) [12].

A fundamental question now arises on the absence of grain orientation effect in our nanoindentation tests, even though a weak effect was obtained during conventional compression tests or indentation tests with $\sim 1 \mathrm{~mm}$ indenter dia in comparison to a strong effect during tensile tests [40]. In our nanoindentation experiments, with tip diameter of $20 \mathrm{~nm}$ and applied load in the $\mathrm{mN}$ range, the nanoindentation shear stress is confined within a single grain and is in the GPa range $(10-15 \mathrm{GPa})$ and the representative strain is relatively high at $8 \%$ (for Berkovich angle of $65.27^{\circ}$ ). This corresponds to a completely developed plastic zone similar to Brinell hardness test [41], such that both favorably and unfavorably oriented grains experience deformation twins, and there is deviation from Schmid's law [36]. In summary, the above discussion and results clearly suggest that the refinement of grain size to the NG regime does not suppress deformation twinning.

\subsection{TEM Study of the Morphology of Plastic Zone as a Function of Strain Rate for the CG Structure}

The objective of the study is to elucidate deformation mechanism in the NG steel and compare with the CG counterpart, which has been previously studied. It is relevant to briefly outline the deformation processes observed in the CG counterpart under identical experimental conditions (strain rate and indentation plastic strain) and compare with NG steel. In contrast to the NG steel, in the CG steel, majority of the reverted austenite transforms to strain-induced martensite ( $\left.\alpha^{\prime}\right)$ comprising of martensite laths at all strain rates, with thickness of the laths decreasing with increasing strain rate. At the highest experimental strain rate of $1 \mathrm{~s}^{-1}$, the $\alpha^{\prime}-$ martensite laths of $\sim 200-300 \mathrm{~nm}$ were present. Previous studies suggested that shear bands are nucleation sites for strain-induced martensite [42,43].

In the CG material, the orientation of austenite grain was compared with the orientation of the transformed strain-induced martensite via selected area electron diffraction analysis. Based on the electron diffraction patterns (e.g. strain rate $0.5 \mathrm{~s}^{-1}$ ), the orientation of the transformed strain-induced martensite from the parent austenite was defined. The orientation relationship between the indented parent austenite and the deformation-induced martensite followed Kurdjumov-Sachs (K-S) orientation relationship, i.e., $\quad\{111\}<110>\gamma / /\{011\}<111>\alpha$. Considering that each of the $24 \mathrm{~K}-\mathrm{S}$ variants have one compressive axis and two tensile axes for 
the martensitic transformation, referred to as the Bain distortion, it is but natural that during nanoindentation or a nanoscale deformation, a variant whose compressive axis of the Bain distortion is almost parallel to the indentation direction, will have a higher probability of selection [25].

\subsection{The Relationship between Mechanical Twinning and Austenite Stability-Strain Energy}

It is clear from sections 3.2 and 3.3 that intense mechanical twinning was an active deformation mechanism in the NG structure (Figure 3 and 4), while strain-induced $\alpha^{\prime}$-martensite was an active deformation mechanism in the CG structure (Figure 6). Twinning and straininduced martensite are both strain hardening mechanisms and prevent strain localization, such that there is an increase in ductility. This is a grain size effect and must be related to enhanced stability of austenite with extensive refinement in grain size, such that twinning is encouraged when the weighted average grain size of steel was $\sim 250 \mathrm{~nm}$. We conclude that there was a distinct transition in the deformation behavior of NG and CG $16 \mathrm{Cr}-10 \mathrm{Ni}$ austenitic stainless steel, such that "twinning" contributed to the excellent ductility of "high strength" NG/UFG steel, while in the "low strength" CG steel, ductility was also high, but because of the TRIP effect from strain-induced martensite.

Grain size governs the thermal stability of austenite [44-46], but the impact on mechanical stability is unclear. The transformation of austenite to martensite introduces anisotropic strain in the adjacent untransformed austenite. The near uniform distribution of transformation strain requires several multi-variant transformations to take place simultaneously within an austenite grain to minimize total strain energy [46]. However, if the austenite grain size is comparable or smaller than the martensite lath, which is applicable in our case, then the possibility of several variants of martensite to occur simultaneously within an austenite grain is decreased because of reduced space. Based on this viewpoint, it is difficult to minimize the strain energy via martensitic transformation in NG/UFG steel. In conclusion, for austenite to transform to martensite via single variant such that the strain energy is reduced on austenite-to-martensite transformation in the NG austenite is not feasible because of spatial restriction effect. This is briefly discussed below. 
The mechanism of refinement of grain size-induced austenite stabilization can be discussed in terms of the physical energy associated with austenite-to-martensitic transformation, and involves equations (6) and (7) [44]:

The increase in elastic strain energy for austenite transform to martensite via single variant mode is given by [44]:

$$
\Delta \mathrm{E}_{\mathrm{V}}=(1 / 2) \mathrm{EI}_{\mathrm{I}} \varepsilon^{2}+(1 / 2) \mathrm{E}_{\mathrm{III}} \varepsilon_{I I}^{2}+(1 / 2) \mathrm{E}_{\mathrm{III}} \varepsilon_{I I I}^{2}
$$

where $\mathrm{E}$ and $\varepsilon$ are Young's modulus and elastic strain in each lattice plane. The FCC to BCC transformation involves lattice displacement and consists of two methods of atomic movement, notably [44] (a) shear deformation of 36\% along [-110] direction and (b) anisotropic deformation accompanying the volume expansion of $\sim 4.5 \%$. The volume expansion of $4.5 \%$ consists of 13.9\% expansion along [001] direction (I direction), 7.0\% contraction along [-110] direction (II direction) and 1.4\% contraction along [-1-10] direction (III direction) [44]. The corresponding Young moduli EI, EII, and EIII are $\sim 132 \mathrm{GPa}, \sim 221 \mathrm{GPa}$, and $221 \mathrm{GPa}$, respectively [44,47] and elastic strains EI, EII, and EIII are 0.139 (expansion), 0.07 (contraction) and 0.014 (contraction), respectively $[44,47]$ in the three directions. The approximate increase in elastic strain energy using equation (6) is $\sim 1840 \mathrm{MJ} / \mathrm{m}^{3}$. Equation (6) can be modified to equation (7):

$$
\Delta \mathrm{E}_{\mathrm{V}}=(1 / 2) \mathrm{E}_{\mathrm{I}} \varepsilon_{\mathrm{I}}^{2}(\mathrm{x} / \mathrm{d})^{2}+\left\{(1 / 2) \mathrm{E}_{\mathrm{II}} \varepsilon_{\mathrm{II}}^{2}+(1 / 2) \mathrm{E}_{\mathrm{III}} \varepsilon_{\mathrm{III}}^{2}\right\}(\mathrm{x} / \mathrm{d})
$$

where $\mathrm{x}$ is the thickness of martensite plate and lattice strain is elastically accommodated in the austenitic grain (grain size: d). Inserting Young's modulus and strain in equation 8, the increase in elastic strain energy is given by:

$$
\Delta \mathrm{E}_{\mathrm{v}}=1276.1(\mathrm{x} / \mathrm{d})^{2}+562.6(\mathrm{x} / \mathrm{d})
$$

For average CG size of $16 \mu \mathrm{m}, \Delta \mathrm{E}_{\mathrm{v}}$ is $\sim 7 \mathrm{MJ} / \mathrm{m}^{3}$ and for $\mathrm{NG}$ structure, $\Delta \mathrm{E}_{\mathrm{v}}$ increases significantly to $\sim 1265 \mathrm{MJ} / \mathrm{m}^{3}$. Thus, the ability to nucleate martensite is minimized with decreasing grain size. In the NG structure, multi-variant transformation is difficult and thus the transformation of austenite to strain-induced martensite transformation is suppressed.

\section{Conclusions}

(i) We have used the phase-reversion process and combined with nanoscale deformation experiments and transmission electron microscopy to study deformation mechanisms and accompanying microstructural evolution in a $16 \mathrm{Cr}-10 \mathrm{Ni} \mathrm{NG}$ austenitic stainless steel and compared with that of the CG counterpart. The strain rate sensitivity of the NG structure was 
greater than the CG counterpart. Using the strain rate sensitivity data, the activation volume of the NG structure was approximately one-half $\left(28 \mathrm{~b}^{3}\right)$ of the CG structure $\left(50 \mathrm{~b}^{3}\right)$.

(ii) In the high strength NG/UFG steel (YS 585 MPa), stacking faults and nanotwins contributed to excellent ductility $(\mathrm{El} \sim 35 \%$ ), while in the case of low strength (YS 260 MPa) coarse-grained (CG) counterpart, ductility was also high (El $\sim 40 \%$ ), but chiefly due to straininduced martensite, which points to a clear case of grain size effect (and the corresponding level of strength).

(iii) Transmission electron microscopy observations as a function of strain rate indicated a distinct transition in the deformation behavior of $16 \mathrm{Cr}-10 \mathrm{Ni}$ NG and CG austenitic steels such that "deformation twinning" contributed to the excellent ductility of the "high strength" NG alloy, while in the "low strength" CG counterpart alloy, ductility was also very good, but because of strain-induced martensitic transformation.

(iv) In the NG structure, there was a monotonic increase in stacking faults and twins with increase in strain rate such that the ratio of stacking faults/twin was reduced with increase in strain rate. This suggested that higher strain rate facilitated the twinning process. The plastic zone in the NG structure resembled a network knitted by intersecting twins and SFs. The twins and SFs did not pass across the whole grain, but stopped in the grain interior with Shockley partial dislocations at the front tips of the twins and SFs. Twinning was envisaged to nucleate by virtue of multiple partial dislocation emissions, which did not require rearrangement of dislocations.

(v) The change in the deformation mechanism from strain-induced martensite in the CG structure to nanoscale twinning in the NG structure is related to the increase in the stability of austenite with decrease in grain size and is explained in terms of austenite stability-strain energy relationship.

Acknowledgements: The authors (R.D.K. Misra, V.S.A. Challa) gratefully acknowledge financial support from National Science Foundation through grant number DMR 1458074. R.D.K.M. and Z.D. Wang also acknowledge support from the National Natural Science Foundation of China through grant $\# 51474064$. 


\section{References}

[1] Ma E, "Instabilities and ductility of nanocrystalline and ultrafine-grained metals," Scripta Mater 2003; 49: 663-668.

[2] Koch $\mathrm{CC}$, "Optimization of strength and ductility in nanocrystalline and ultrafine-grained metals," Scripta Mater 2003; 49: 657-662.

[3] Misra RDK, Thompson SW, Hylton TA, Boucek AJ, "Microstructures of hot-rolled highstrength steels with significant differences in edge formability," Metall. Mater. Trans. A 2001; 32: 745-760.

[4] Misra RDK, Tenneti KK, Weartherly GC, Tither G, "Microstructure and texture of hot-rolled $\mathrm{Cb}-\mathrm{Ti}$ and $\mathrm{V}-\mathrm{Cb}$ microalloyed steels with differences in formability and toughness," Metall. Mater. Trans A 2003; 34: 2341-2351.

[5] Misra RDK, Nathani H, Hartmann JE, Siciliano F, "Microstructural evolution in a new 770 MPa hot rolled Nb-Ti microalloyed steel,” Mater. Sci. Eng. A 2005; 394: 339-352.

[6] Shanmugam S, Misra RDK, Hartmann JE, Jansto S, "Impact toughness and microstructure relationship in niobium- and vanadium-microalloyed steels processed with varying cooling rates to similar yield strength,” Mater. Sci. Eng. A 2006; 437: 436-445.

[7] Song R, Ponge D, Rabbe D, Kasper R, "Microstructure and crystallographic texture of an ultrafine-grained C-Mn steel and their evolution during warm deformation and annealing," Acta Mater. 2005; 53: 845-858.

[8] Humphreys FJ, Prangnell PB, Bowen JR, Gholina A, Harris C, "Developing stable fine-grain microstructures by large strain deformation,” Philos. Trans. Roy. Soc. London, Ser. A 1999; 357: 1663-1681.

[9] Misra RDK, Nayak S, Venkatasurya P, Ramuni V, Somani M, Karjalainen LP, "Nanograined/ultrafine-grained structure and tensile deformation behavior of shear phasereversion induced 301 austenitic stainless steel," Met. Mater. Trans A 2010; 41: 2162-2174.

[10] Misra RDK, Nayak S, Mali S, Shah J, Somani M, Karjalainen LP, ”On the significance of nature of strain-induced martensite on phase-reversion induced nangrained/ultrafine-grained austenitic stainless steel," Met. Mater. Trans A 2010; 41: 3-12.

[11] Misra RDK, Venkatasurya PKC, Somani M, Karjalainen LP, "Nanoscale deformation behavior of phase-reversion induced austenitic stainless steel: The interplay between grain 
size from nanograin regime to coarse-grained regime," Met. Mater. Trans A 2012; 43A: 5286-5297.

[12] Misra RDK, Challa VSA, Venkatsurya PKC, Shen YF, Somani MC, and Karjalainen LP, "Interplay between grain structure, deformation mechanisms and austenite stability in phase-reversion-induced nanograined/ultrafine-grained austenitic ferrous alloy," Acta Mater. 2015; 84: 339-348.

[13] Challa VSA, Misra RDK, Somani MC, and Wang ZD, "Strain hardening behavior of nanograined/ultrafine-grained (NG/UFG) austenitic $16 \mathrm{Cr}-10 \mathrm{Ni}$ stainless steel and its relationship to austenite stability and deformation behavior," Materials Science and Engineering A, 2016: 649: 153-157.

[14] Shen F, Zhou J, Liu Y, Zhu R, Zhang S, Wang Y, "Deformation twinning mechanism and its effects on the mechanical behaviors of ultrafine grained and nanocrystalline copper," Compt. Mater. Sci. 2010; 49: 226-235.

[15] Cheng S, Stoica AD, Wang X-L, Ren Y, Almer J, Horlon JA, Liu CT, Zuo L, ’Deformation crossover: From nano- to mesoscale," Phys. Rev. Lett. 2009; 103: 035502.

[16] Capolungo L, Cherkaoui M, Qu J, "On the elastic-viscoplastic behavior of nanocrystalline materials,” Int. J. Plast. 2007; 23: 561-591.

[17] Nohara K, Ono Y, Ohashi N, "Composition and grain size dependencies on strain-induced martensitic transformation in metastable austenitic stainless steel,” J. Iron Steel Inst. Jpn 1977; 63: 772-778.

[18] Frehn A, Ratte E, Bleck W, Steel Grips, 2004; 2: 447-462.

[19] Turtletaub S, Suiker ASJ, “Grain size effects in multiphase steels assisted by transformationinduced plasticity,” Inter. J. Solids and Mechanics 2006; 43: 7322-7336.

[20] Lu L, Schwaiger R, Shan ZW, Dao M, Lu K, Suresh S, "Nano-sized twins induce high rate sensitivity of flow stress in pure copper," Acta Mater. 2005; 53: 2169-2179.

[21] Schwaiger R, Moser B, Dao M, Chollacoop N, Suresh S, "Some critical experiments on the strain-rate sensitivity of nanocrystalline nickel," Acta Mater. 2003; 51: 5159-5172.

[22] Yang B, Vehoff H, Pippan R, "Overview of the grain size effects on the mechanical and deformation behavior of electrodeposited nanocrystalline nickel-from nanoindentation to high pressure torsion,” Mat. Sci. Forum 2010; 633-634: 85-98. 
[23] Vehoff H, Lemaire D, Schuler K, Waschkies T, Yang B, "The effect of grain size on strain rate sensitivity and activation volume - from nano to UFG nickel,” Intern. J. Mat. Res. 2007; 98: 259-268.

[24] Jin M, Minor AM, Ge D, Morris JW, "Study of deformation behavior on ultra-fine grained materials through in situ nanoindentation in a TEM,” J. Mater. Res. 2005; 20: 1735-1740.

[25] Ahn T-H, Oh C-S, Kim DH, Bei H, George EP, Han HN, "Investigation of strain-induced martensitic transformation in metastable austenite using nanoindentation," Scripta Mater 2010; 63: 540-543.

[26] Rajasekhara S, Ferreira PJ, Karjalainen LP, Kyrolainen KA, "Hall-petch behavior in ultrafine-grained AISI 301LN stainless steel,” Met. Mater. Trans. A. 2007; 38: 1202-1210.

[27] Schuh CA, Nieh TG, Kawamura Y, "Rate dependence of serrated flow during nanoindetation of a bulk metallic glass,” J. Mater. Res. 2002; 17: 1651-1654.

[28] Asaro RJ, Suresh S, "Mechanistic models for the activation volume and rate sensitivity in metals with nanocrystalline grains and nano-scale twins," Acta Mater 2005; 53: 3369-3382.

[29] Lu L, Schwaiger R, Shan ZW, Dao M, Lu K, Suresh S, "Nano-sized twins induce high rate sensitivity of flow stress in pure copper," Acta Mater. 2005; 53: 2169.

[30] Maier V, Durst K, Mueller J, Backes B, Hoppel HW, Goken M, "Nanoindentation strain rate jump tests for determining the local strain rate sensitivity of nc-Ni and ufg-Al," J. Mater. Res. 2011; 26: 1421-1430.

[31] Yamakov V, Wolf D, Phillpot SR, Gleiter H, "Dislocation-dislocation and dislocation-twin reactions in nanocrystalline Al by molecular dynamics simulation," Acta Mater 2013; 51: 4135-4147.

[32] Zhu YT, Liao XZ, Srinivasan SG, Lavernia EJ, "Nucleation of deformation twins in nanocrystalline face-centered-cublic metals processed by severe plastic deformation, “ J. App1. Phys. 2005; 98: 034319-1-8.

[33] Wang J, Huang HC, "Shockley partial dislocations to twin: Another formation mechanism and generic driving force," Appl. Phys. Letter. 2004; 85: 5983-5985.

[34] Lagerlof KPD, Castaing J, Pirouz P, Heuer AH, "Nucleation and growth of deformation twins: a perspective based on the double-cross-slip mechanism of deformation twinning," Phil. Mag. 2002; 82: 2841-2854. 
[35] Jian WW, Cheng GM, Xu WZ, Yuan H, Tsai MH, Wang QD, Koch CC, Zhu YT, Mathaudhu SN, "Ultrastrong Mg alloy via nano-spaced stacking faults," Mater. Res. Lett., 2013; 1: 61-66.

[36] Gutierrez-Urrutia I, Zaefferer S, Raabe D, "The effect of grain size and grain orientation on deformation twinning in a Fe-22wt.\%Mn-0.6wt.\%C TWIP steel,” Mater. Sci Eng. A, 2010; 527: 3552-3560.

[37] Ueji R, Tsuchida N, Terada D, Tsuji N, Tanaka Y, Takemura A, Kunishige K, “Tensile properties and twinning behavior of high manganese austenitic steel with fine-grained structure," Scripta Mater. 2008; 59: 963-966.

[38] Yang P, Xie Q, Meng L, Ding H, Tang Z, "Dependence of deformation twinning on a grain orientation in high manganese steel," Scripta Mater. 2006; 55: 629-631.

[39] Meng L, Yang P, Xie Q, Ding H, Tang Z, "Dependence of deformation twinning on grain orientation in compressed high manganese steels," Scripta Mater. 2007; 56: 931-934.

[40] Gussev MN, Busby JT, Byun TS, Parish CM, "Twinning and martensitic transformations in nickel-enriched 304 austenitic stainless steel during tensile and indentation deformations," Mater. Sci. Eng A. 2013; 588: 299-307.

[41] Nanoindentation, Anthony C. Fischer-Cripps, Second Edition, Springer-Verlag, New York (2004)

[42] Talonen J, Hanninen H, "Formation of shear bands and strain-induced martensite during plastic deformation of metastable austenitic stainless steels," Acta. Mater. 2007; 55: 61086118.

[43] Hedström P, Lindgren LE, Almer J, Lienert U, Bernier J, Terner M, Oden M, "Load partitioning and strain-induced martensite formation during tensile loading of a metastable austenitic stainless steel," Met. Mat Trans. A 2009; 40A: 1039-1048.

[44] Takaki S, Fukunaga K, Syarif J, Tsuchiyama T, "Effect of grain refinement on thermal stability of metastable austenitic stainless steel," Materials Transactions, 2004; 45: 22452251.

[45] Jimenez-Melero E, van Dijk NH, Zhao L, Sietsma J, Offerman SE, Wright JP, van der Zwaag S, "Martensitic transformation of individual grains in low-alloyed TRIP steels," Scripta Mater, 2007; 56: 421-424. 
[46] Matsuoka Y, Iwasaki T, Nakada N, Tsuchiyama T, Takaki S, "Effect of grain size on thermal and mechanical stability of austenite in metastable austenitic stainless steel," ISIJ Int., 2013; 53: $1224-1230$.

[47] Yamamoto S, Asabe K, Nishiguchi M, Maebara Y, "Recrystallization texture and young's modulus of ceramic particle dispersed ferrite steel bars," Tetsu-to-Hagane' 1996; 82: 771776. 

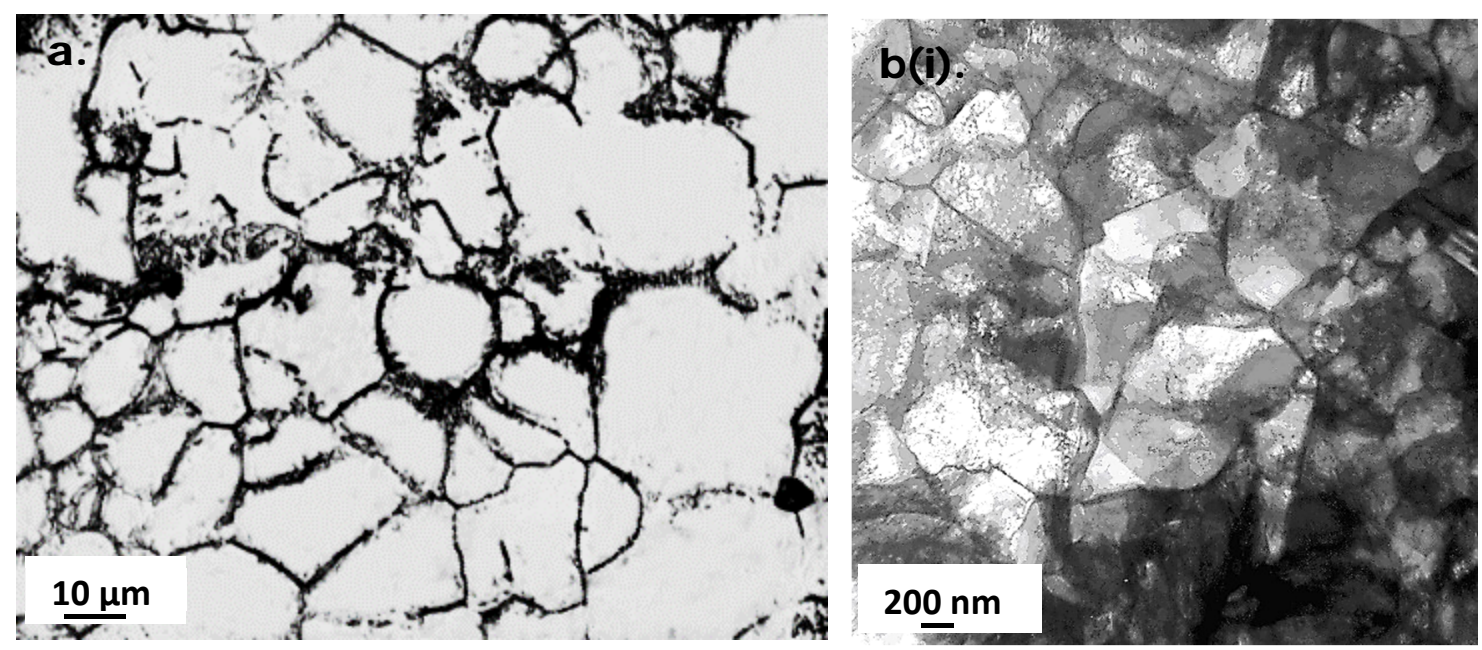

Figure 1. (a) Light micrograph of coarse-grained (CG) and (b) representative transmission electron micrographs of nanograined (NG) 16Cr-10Ni austenite stainless steels [13]. 


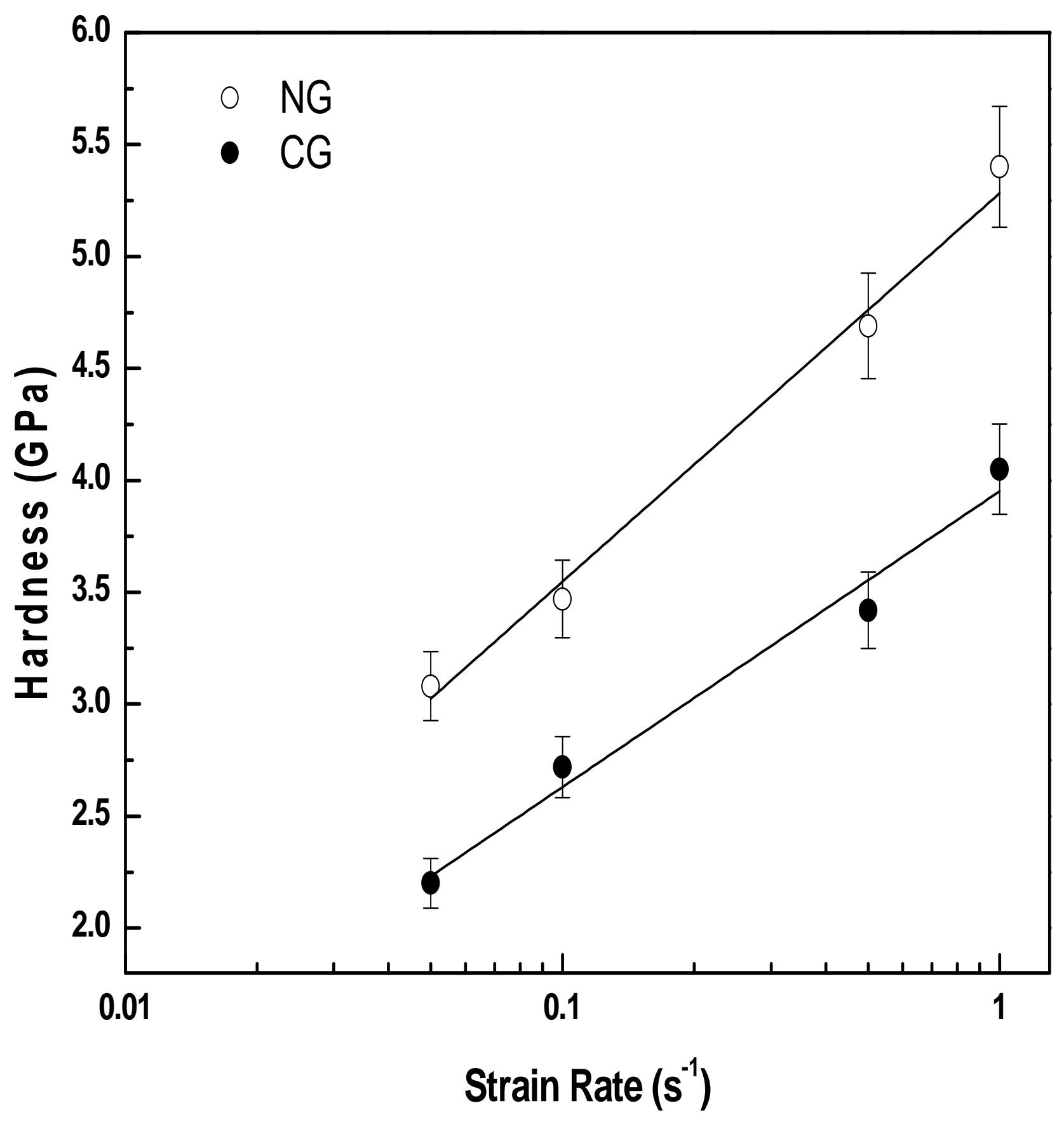

Figure 2. Hardness versus strain rate plots for (a) CG and (b) NG 16Cr-10Ni austenitic stainless steel obtained using depth-sensing nanoindentation experiments. 

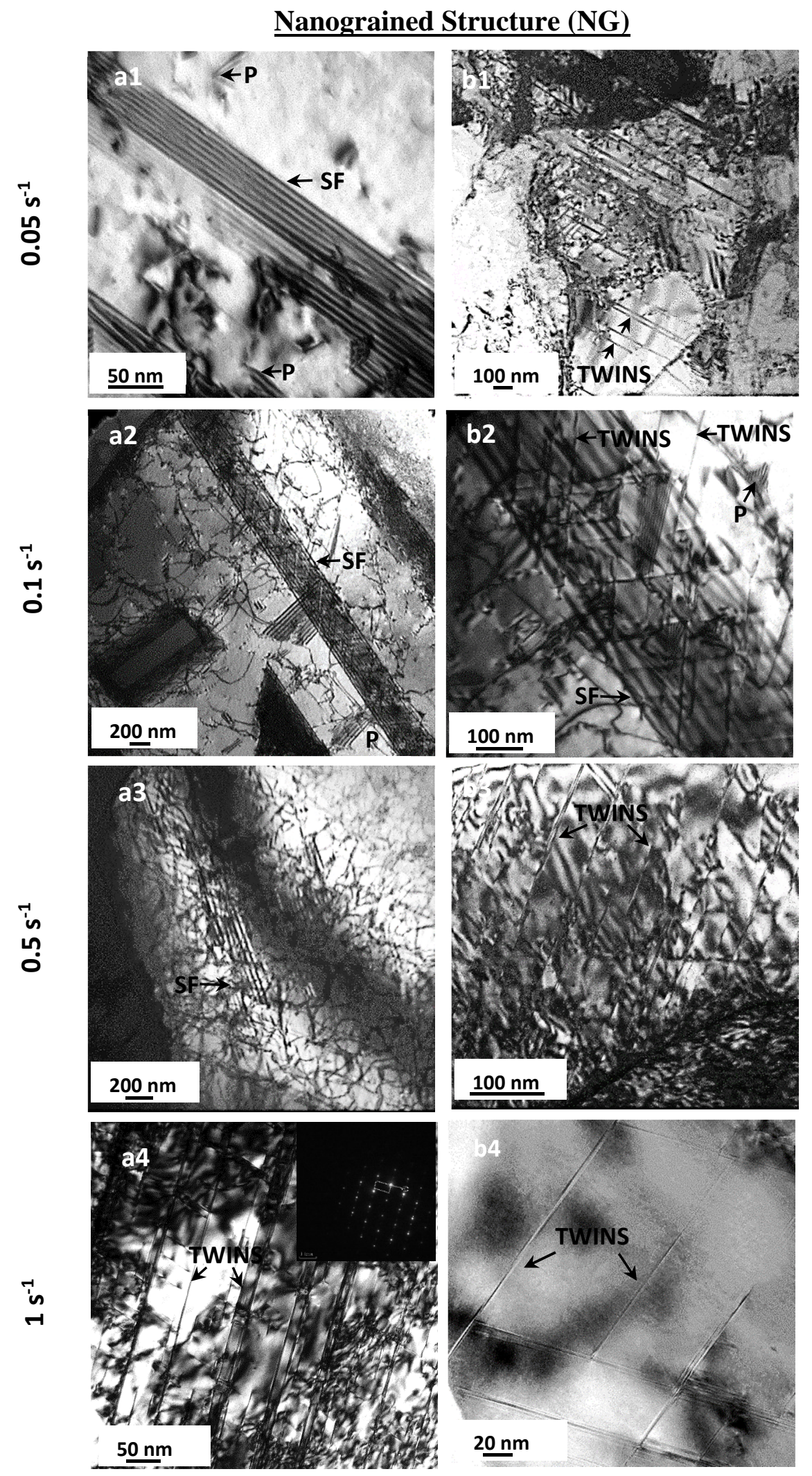

Figure 3. Summary of TEM observations of the morphologies of the plastic zone surrounding the indentation after indentation experiments with various strain rates for $\mathrm{NG} 16 \mathrm{Cr}-10 \mathrm{Ni}$ austenitic stainless steel. 

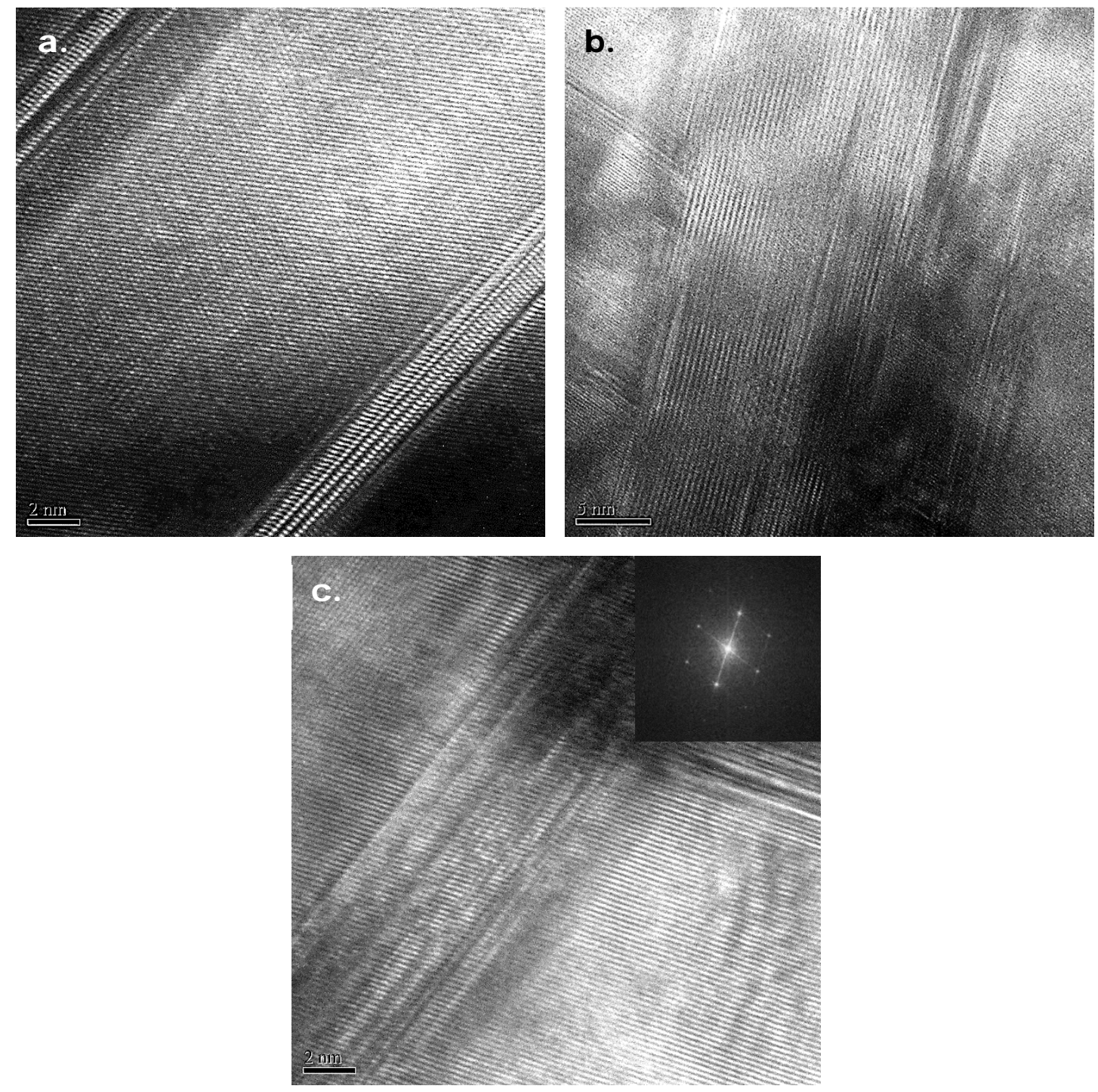

Figure 4. Representative examples of high magnification transmission electron micrographs illustrating deformation twins in NG 16Cr-10Ni stainless steel. 


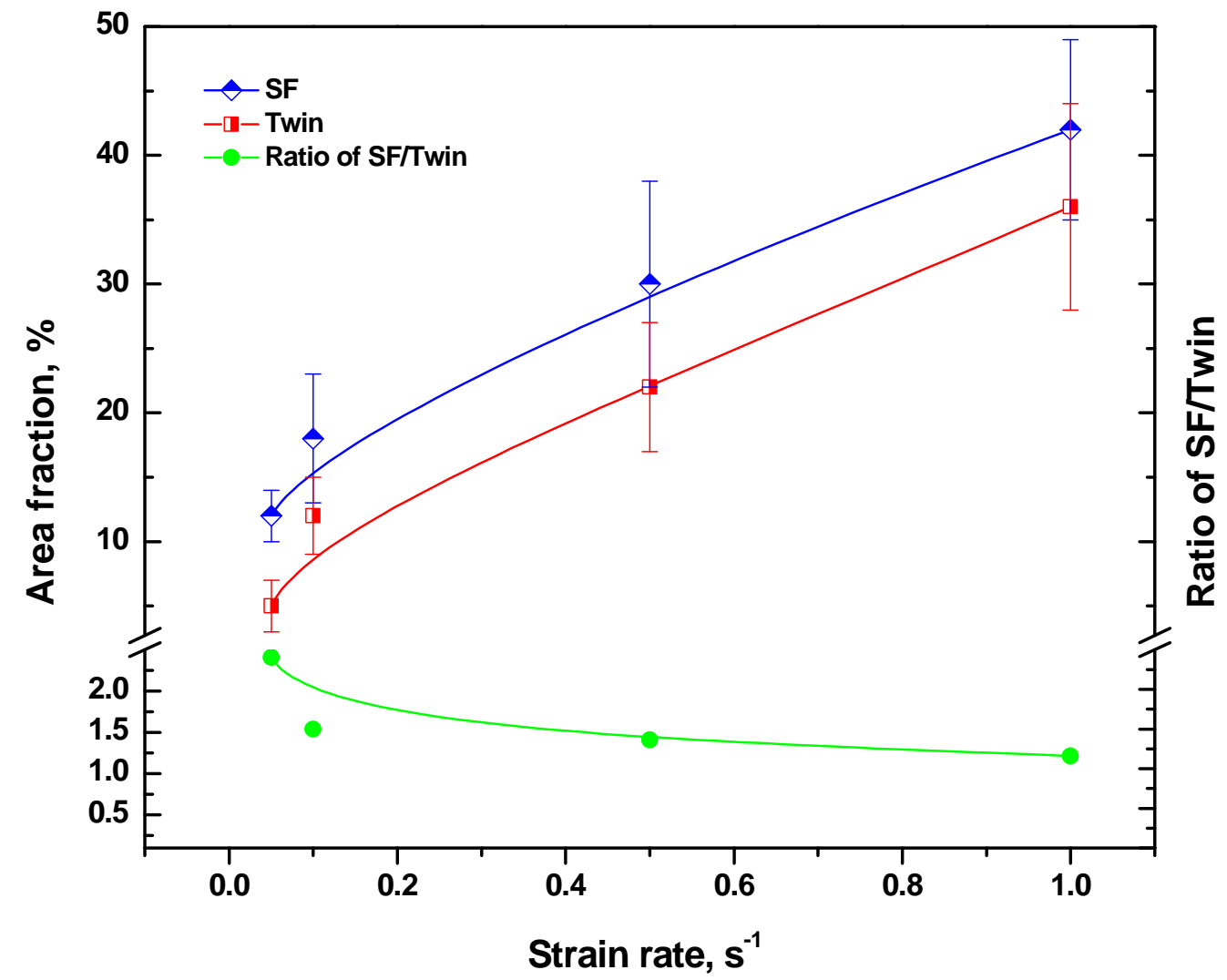

Figure 5. The evolution of stacking faults (SFs) and twin area fraction and also the ratio of $\mathrm{SF} / \mathrm{twin}$ as a function of strain rate. 



Figure 6. Summary of TEM observations of the morphologies of the plastic zone surrounding the indentation after indentation experiments with various strain rates for CG $16 \mathrm{Cr}-10 \mathrm{Ni}$ austenitic stainless steel. 